\title{
PENINGKATAN PENGETAHUAN ANAK SD MELALUI EDUKASI GIZI TENTANG MAKANAN JAJANAN SEHAT DAN GIZI SEIMBANG DENGAN MEDIA BUKU CERITA BERGAMBAR DI SD TIYARAN 01 DAN 03 SUKOHARJO
}

\author{
Eni Purwani dan Muwakhidah \\ Program Studi Ilmu Gizi \\ Fakultas Ilmu Kesehatan \\ Unversitas Muhammadiyah Surakarta \\ J1. A. Yani Tromol Pos I Pabelan, Kartasura, Surakarta, Indonesia \\ Emai : eni.purwani@ums.ac.id
}

\begin{abstract}
There are so many snack that sold at the school that has a high risk for the health. Range from snak that consume by student have a potential occur the contamination biology or chemical that disturb the health according the long term or the short term. In generally, the seller of the snack didn't know the food safety that they sold. And so do the student at Tiyaran 1 and 3 Elementary School didn't really know about the healthy snack. This activity is promotif and preventif efforts, so the student can know and understanding the healthy snack in the school also can do the protection toward dangerous food material. The methode that use for this activity is giving education through the media Pictorial Story Book that has content about things that concern the snack at the school that created in the form pictorial story that simple and interesting. The purpose using media pictorial story book is to be the participant to easy undertanding the material. Beside that do the demonstration test the dangerous substance that consist of Formalin test, Borax, and the food colour that dangerous such as Methanil Yellow and Rhodamin B. This education activity can improve the elementary student's knowledge, teacher's, and canteen organizer's about the healthy snack. Beside that, also improve the knowledge about the dangerous material with test the snack at the school with reagen test to detect the existency of formalin, borax, methanil yellow, rhodamin $B$.
\end{abstract}

Keywords: The school student's snack, education, Pictorial Story Book

\section{PENDAHULUAN}

Sekolah secara umum hampir tidak bisa dipisahkan dari penjual jajanan, dimana ada sekolah maka di tempat tersebut juga terdapat penjual jajanan disekitarnya. Kondisi ini bisa dipahami karena siswa sekolah adalah pangsa potensial bagi para penjual makanan.

Keberadaan penjual jajanan menjadi faktor penting karena terkait dengan asupan makanan bagi siswa. Kegiatan di sekolah telah menyita waktu cukup besar dalam aktivitas sehari hari, termasuk aktifitas makan. Pada umumnya anak sekolah, selain mengkonsumsi makanan di rumah juga memiliki kebiasaan membeli jajan di sekolah. Mutu makanan jajanan terutama mutu gizi sangat mempengaruhi kondisi asupan makanan pada anak. Hal ini harus menjadi perhatian karena jajanan menjadi bagian yang memberi kontribusi asupan pangan pada. Jika jajanan yang dikonsumsi anak sehat, maka akan berpengaruh 
terhadap perkembangan dan kesehatan anak. Demikian juga sebaliknya, jika jajanan yang dikonsumsi anak tidak sehat, maka akan mempengaruhi perkembangan dan kesehatan anak.

Ada banyak jenis jajanan yang umumnya dijual disekitar sekolah seperti lontong, otakotak, tahu goreng, mie bakso dengan saus, ketan uli, es sirop dan cilok. Kebanyakan jajanan tersebut umumnya telah mengalami pencemaran kimiawi karena menggunakan Bahan Tambahan Pangan (BTP) ilegal seperti borax (pengempal yang mengandung logam berat Boron), formalin (pengawet yang digunakan untuk mayat), rhodamin $B$ (pewarna merah pada tekstil), dan methanyl yellow (pewarna kuning pada tekstil). Bahanbahan ini dapat terakumulasi pada tubuh manusia dan bersifat karsinogenik yang dalam jangka panjang menyebabkan penyakitpenyakit seperti antara lain kanker dan tumor pada organ tubuh manusia. Pengaruh jangka pendek penggunaan BTP ini menimbulkan gelaja-gejala yang sangat umum seperti pusing dan mual. Joint Expert Committee on Food Additives (JECFA) dari WHO yang mengatur dan mengevaluasi standar BTP melarang penggunaan bahan kimia tersebut pada makanan. Standar ini juga diadopsi oleh Badan POM dan Departemen Kesehatan RI melalui Peraturan Menkes no. 722/Menkes/ Per/IX/1998 (WHO, 2000)

Pada umumnya para penjual jajanan dengan kandungan bahan yang berbahaya bagi kesehatan beralasan karena tidak tahu adanya BTP ilegal pada bahan baku jajanan yang mereka jual. Resiko lain selain adanya BTP berbahaya, banyak makanan yang dijajakan oleh penjual jajanan anak pada umumnya tidak dipersiapkan secara baik. Mereka umumnya kurang memperhatikan aspek kebersihan dan higenitas seperti pembuatan es dari air mentah, jajanan dibiarkan terbuka, tempat cucian yang tidak bersih termasuk tidak memperhatikan sanitasi disekitar tempat berjualan.

Di sisi lain, siswa dan pengelola kantin sekolah tidak memiliki cukup pengetahuan dalam memilih jajanan. Mereka membeli jajanan sesuai dengan seleranya tanpa memperhatikan baik buruknya bagi kesehatan. Kondisi ini diperparah dengan kebiasaan anak jajan di sekolah. Seolah-olah jajan sudah menjadi wajib bagi sebagian besar siswa. Jajan di sekolah juga sudah menjadi bagian dari budaya sekolah. Mudahnya akses dalam membeli jajanan juga dikarenakan akses transportasi saat ini yang menyebabkan banyak penjual makanan jajanan di sekolahsekolah yang letaknya berada di pinggir jalan, termasuk SD Tiyaran 1 dan 3 yang terletak di pingggir jalan alternatif yang menghubungkan Wonogiri, Sukoharjo dan Klaten.

SD Tiyaran 1 dan 3 terletak di Desa Tiyaran Kecamatan Bulu, Kabupaten Sukoharjo. Posisi sekolah ini berjarak sekaitar 4 kilometer dari ibu kota kecamatan dan 23 kilometer dari pusat Kota Kabupaten Sukoharjo. Jarak SD Tiyaran I dari Kampus Universitas Muhammadiyah Surakarta kurang lebih sekitar 40 KM.. Mudahnya akses transportasi di SD Tiyaran 1 dan 3 membuat sekolah ini ramai dikunjungi penjual jajanan terutama pada saat jam istirahat. Para penjual jajanan itu umumnya menggunakan lapak yang diletakkan di atas sepeda atau kendaraan bermotor. Mereka yang berjualan jajanan itu ada yang berasal dari luar desa, akan tetapi kebanyakan dari mereka adalah warga sekitar sekolah.

SD Tiyaran 1 tersedia dua kantin yang berada di area dalam sekolah, sedang SD Tiyaran 3 mempunyai 1 kantin. Seperti penjual jajan pada umumnya, kantin sekolah juga menjual aneka jajanan. Kebanyakan jajanan yang dijual di kantin adalah jajan pabrikan seperti makanan ringan, biskuit, jajanan kemasan yang beraneka rasa dan warna menyolok serta aneka minuman. Selain itu ada pula aneka jajanan lain seperti cilok, tempura, bakso bakar, otak-otak dll.

Permasalahan di SD Tiyaran 1 dan 3 meliputi: (1) Banyak jajanan tidak sehat dijual di sekolah, (2) Siswa punya kebiasaan jajan di sekolah, (3) Tidak ada media dari sekolah untuk transfer pengetahuan jajanan sehat, (4) Pihak sekolah tidak mampu untuk melarang 
para penjual jajanan yang berada disekitar sekolahan mengingat umumnya penjual jajanan adalah warga sekitar sekolahan, (5) Pihak sekolah juga tidak memiliki kapasitas untuk melakukan edukasi kepada siswa dan tidak memiliki kapasitas pelatihan pada pengelola kantin sekolah agar mampu menyediakan jajanan sehat, (6) Pengetahuan pihak kantin kurang terhadap keamanan pangan maupun jenis-jenis jajanan sehat.

Berdasarkan permasalahan tersebut maka pentingnya edukasi gizi tentang makanan jajanan sehat pada anak SD dan pengelola kantin untuk meningkatkan pengetahuan dan menambah wawasan tentang kesehatan dan gizi seimbang.

\section{TUJUAN}

Tujuan dari kegiatan ini adalah meningkatkan pengetahuan anak SD Tiyaran 1 dan 3 tentang makanan jajanan sehat dan gizi seimbang bagi anak SD dan pengelola kantin.

\section{TARGET DAN LUARAN}

Target kegiatan ini adalah membantu sekolah dalam meningkatkan kapasitasnya terhadap makanan jajanan yang tidak sehat bagi siswa dan siswinya melalui pendidikan dengan media buku cerita bergambar yang melibatkan pihak pengelola kantin sekolah. Dengan adanya kegiatan ini, siswa tertarik untuk membaca pesan-pesan tentang makanan yang aman maupun tidak aman, yang dikemas dalam bentuk buku cerita bergambar. Pemahaman siswa semakin meningkat dengan didukung adanya demonstrasi dalam menguji bahan-bahan berbahaya yang terdapat pada jajanan yaitu adanya formalin, borak mapun pewarna yang berbahaya. Kegiatan ini juga melibatkan kantin sekolah, sehingga pengelola kantin dapat mengetahui jajanan yang aman untuk dikonsumsi siswa dengan didukung kantin yang menjual jajanan yang sehat.

Luaran dari kegiatan ini, siswa paham jajanan yang sehat (aman) maupun yang tidak sehat/tidak aman. Pihak kantin juga memiliki pemahaman tentang jajanan tersebut sehingga mampu menyediakan jenis-jenis jajanan yang sehat untuk dikonsumsi siswa di sekolah tersebut.

\section{METODE KEGIATAN}

Kegiatan ini merupakan upaya promotif dan preventif agar siswa dapat mengetahui dan memahami makanan jajanan yang sehat di sekolah serta dapat melakukan proteksi atau perlindungan terhadap bahan makanan berbahaya. Proteksi yang dimaksud bukan melarang siswa membeli jajanan di lingkungan sekolah, karena hal itu akan sulit dilakukan. Pengertian proteksi di sini adalah memberikan edukasi kepada siswa agar mereka selektif dalam memilih jajanan dan melatih kantin sekolah menyediakan jajanan sehat.

Metode yang digunakan dalam kegiatan ini adalah Pemberian edukasi melalui media Buku Cerita Bergambar yang berisi tentang hal-hal terkait jajanan di sekolah yang dikemas dalam bentuk cerita bergambar yang sederhana dan menarik. Tujuan menggunakan media buku cerita bergambar adalah agar peserta mudah memahami dan mencerna materi. Disamping itu juga dilakukan demonstrasi uji zat berbahaya pada jajanan yang meliputi Uji Formalin, Boraks, dan pewarna makanan yang berbahaya yaitu Methanil Yellow dan Rhodamin B.

\section{HASIL DAN PEMBAHASAN}

\section{A. PELAKSANAAN KEGIATAN}

Kegiatan pengabdian masyarakat ini dilakukan dengan berbagai tahap kegiatan. Survei lokasi pada bulan Februari 2015 dilakukan untuk memberikan gambaran permasalahan yang dihadapi oleh mitra baik di SDN Tiyaran 1 maupun SDN Tiyaran 3. Berdasarkan permasalahan dari mitra, dibuat pemetaan kegiatan untuk memberikan solusi pada permasalahan tersebut. Rapat koordinasi dilakukan baik antar tim pengabdian maupun dengan pihak mitra pada bulan Januari 2016 hingga Apri 2016, agar kegiatan dapat berjalan lancar.

Tahapan-tahapan kegiatan pengabdian masyarakat di SDN Tiyaran 1 maupun SDN 
Tiyaran 3 meliputi :

1. Edukasi Jajanan Sehat melalui kegiatan pendidikan/penyuluhan dengan media buku cerita bergambar pada siswa, guru dan pengelola kantin

2. Edukasi Jajanan Sehat melalui Demonstrasi cara menguji berbagai jajanan yang mengandung zat berbahaya atau tidak dengan kit reagen pada siswa, guru dan pengelola kantin

\section{B. HASIL KEGIATAN}

1. Edukasi Jajanan Sehat melalui Kegiatan Pendidikan/Penyuluhan

Kegiatan ini dilakukan pada hari Selasa tanggal 26 Juli 2016 bertempat di ruang kelas SDN Tiyaran 1. Sebelum dan sesudah dilakukan pendidikan jajanan sehat dengan media buku cerita bergambar, dilakukan pretest dan post test pada semua siswa, guru dan pengelola kantin. Kegiatan ini dilakukan untuk mengetahui pemahaman mereka selama dilakukan pendidikan.

Pada waktu kegiatan pendidikan jajanan sehat berlangsung, terlihat siswa, guru dan pengelola kantin antusias dalam mengikuti kegiatan tersebut. Siswa dalam memahami isi buku cerita bergambar didampingi oleh mahasiswa yang terlibat dalam tim pengabdian ini. Pendampingan ini terutama untuk siswa kelas 1 dan 2 yang belum lancar membaca buku cerita bergambar. Selama kegiatan berlangsung terlihat siswa tertarik untuk membaca pesan-pesan tentang makanan yang aman maupun tidak aman, yang dikemas dalam bentuk buku cerita bergambar.

Sebelum dan sesudah dilakukan pendidikan jajanan sehat dengan media buku cerita bergambar, dilakukan pretest dan post test pada semua siswa, guru dan pengelola kantin. Kegiatan ini dilakukan untuk mengetahui pemahaman mereka selama dilakukan pendidikan.

Pada waktu kegiatan pendidikan jajanan sehat berlangsung, terlihat siswa, guru dan pengelola kantin antusias dalam mengikuti kegiatan tersebut. Siswa dalam memahami isi buku cerita bergambar didampingi oleh mahasiswa yang terlibat dalam tim pengabdian ini. Pendampingan ini terutama untuk siswa kelas 1 dan 2 yang belum lancar membaca buku cerita bergambar. Selama kegiatan berlangsung terlihat siswa tertarik untuk membaca pesan-pesan tentang makanan yang aman maupun tidak aman, yang dikemas dalam bentuk buku cerita bergambar.

\section{Demonstrasi Uji Berbagai Jajanan yang Mengandung Zat Berbahaya atau Tidak Berbahaya}

Kegiatan demonstrasi ini melibatkan mahasiswa Prodi Ilmu Gizi Fakultas Ilmu Kesehatan UMS. Berbagai jajanan yang dijual di kantin yang berwarna warni baik makanan maupun minuman diuji dengan kit boraks, formalin, pewarna sintetis methanyl yellow maupun rhodamin $B$.

Jajanan yang diuji pada kegiatan ini adalah jenis-jenis jajanan yang biasa dijual di kantin SDN Tiyaran 1 maupun SDN Tiyaran 3 , seperti jajanan chiki-chikian, selai warnawarni maupun minuman yang berwarna warni. Pemahaman siswa tentang jajanan yang tidak sehat, semakin meningkat dengan didukung adanya demonstrasi ini. Kegiatan ini juga melibatkan pengelola kantin sekolah, sehingga pengelola kantin dapat mengetahui jajanan yang aman maupun tidak aman untuk dikonsumsi siswa.

Setelah kegiatan demonstrasi uji kit pada jajanan, dilakukan serah terima Reagen Kit kepada pihak sekolah melalui kepala sekolah kedua sekolah tersebut. Pemberian reagen kit kepada SDN Tiyaran 1 maupun SDN Tiyaran 3 bertujuan untuk memantau pihak kantin sekolah dalam menyediakan berbagai jajanan untuk siswanya.

\section{KESIMPULAN DAN SARAN}

\section{A. SIMPULAN}

Meningkatnya pengetahuan jajanan yang sehat dan tidak sehat pada siswa, guru sekolah dan pengelola kantin sekolah

Pihak sekolah mampu menguji berbagai jajanan dengan reagen kit boraks, formalin, pewarna sintetis methanyl yellow dan 
rodhamin B

\section{B. SARAN}

Saran pada kegiatan ini, setelah dilakukan follow-up pada siswa dan pengelola kantin, pihak sekolah terus memantau siswanya dalam mengkonsumsi jajanan selama kegiatan di sekolah berlangsung.

\section{UCAPAN TERIMA KASIH}

Pengabdian masyarakat terkait Keamanan Makanan jajanan di sekolah di wilayah Kabupaten Sukoharjo ini tidak lepas dari peran institusi pendidikan. Universitas Muhammadiyah Surakarta merupakan Perguruan Tinggi Swasta terbesar di wiilayah Surakarta yang hampir setiap tahun terdapat proposal IbM yang didanai oleh Dikti. UMS memiliki lembaga yang sangat berperan di bidang pengabdian yaitu Lembaga Penelitian dan Pengabdian Masyarakat (LPPM) UMS. Hal ini sesuai dengan visinya yaitu Menjadi lembaga pemberdaya dan pengembang masyarakat yang handal dalam memberikan arah perubahan masyarakat, terutama masyarakat Jawa Tengah menuju masyarakat yang madani, mandiri dan sejahtera secara berkelanjutan.

Kegiatan ini berjalan dengan lancar juga tidak lepas dari kerja sama dan partisipasi dari berbagai pihak, Kami mengucapkan banyak terima kasih kepada Kepala Sekolah, Bapa ibu Guru, pengelola kantin dan siswa SD Tiyaran 1 dan 3 yang telah mengikuti dan berpartisipasi aktif dalam pelaksanaan kegiatan ini. Semoga kegiatan ini dapat bermanfaat dan ditindaklanjuti oleh pihak sekolah untuk meningkatkan kualitas sumber daya manusia dan generasi penerus bangsa.

\section{DAFTAR PUSTAKA}

BPOM. 2006. Keamanan Pangan Jajan Anak Sekolah (PJAS). BPOM NA-DFC. Jakarta.

FAO. 1997. Street Foods. Report Of An FAO Technical Meeting On Street Foods, Calcutta, 6-9 November 1995. FAO Food And Nutrition Paper 63. FAO, Rome.

Judarwanto Widodo, 2006. Perilaku Makan Anak Sekolah. Children Allergen Center. Jakarta.

Kaem, D. 2007. Pengetahuan Keamanan Pangan : Tentang Pewarna. www.tonangardyanto. com.

WHO. 2000. Foodborne Disease: A Focus For Health Education. World Health Organization, Geneva.

WHO/ICD/SEAMEO. 1999. Persyaratan Utama Keamanan Makanan Jajanan Kaki Lima. (Terjemahan). SEAMEO TROPMED RCCN UI. Jakarta. 